\title{
CONTROLE EM PÓS-EMERGÊNCIA DE PLANTAS DANINHAS POR HERBICIDAS UTILIZADOS NA CULTURA DA CANA-DE-AÇÚCAR ${ }^{1}$
}

\author{
PAULO VINICIUS DA SILVA² ${ }^{2 *}$ PATRÍCIA ANDREA MONQUERO³, WILLIAM SANCHES MUNHOZ ${ }^{4}$
}

\begin{abstract}
RESUMO - A implantação do sistema de colheita mecanizada de cana-de-açúcar resultou em alterações no sistema produtivo, dentre elas a modificação da flora infestante, haja vista a promoção do surgimento de espécies de plantas daninhas que antes não eram recorrentes nos canaviais. Diante do exposto, o presente trabalho teve como objetivo determinar curvas de dose resposta dos herbicidas amicarbazone, saflufenacil, mesotrione e sulfentrazone em pós-emergência no controle das plantas daninhas Merremia aegyptia, Ipomoea purpurea, Luffa aegyptiaca, Mucuna aterrima e Ricinus communis. O experimento foi realizado em casa de vegetação, em delineamento inteiramente casualizado, com quatro repetições. Os tratamentos constituíram da aplicação das diferentes doses dos herbicidas sobre as plantas daninhas M. aegyptia, I. purpúrea, L. aegyptiaca, M. aterrima e $R$. communis quando estas se encontravam no segundo par de folhas verdadeiras. O método utilizado foi o de curva de dose resposta, sendo aplicadas doses equivalentes a 1,5, 1,0, 0,5, 0,25 e 0,00 vezes a dose comercial de cada produto (amicarbazone, saflufenacil, mesotrione e sulfentrazone). Aos 7, 14 e 21 dias após as aplicações dos tratamentos (DAT) foram avaliados visualmente o controle, e aos 21 DAT determinada a massa seca da parte aérea. O amicarbazone e sulfentrazone na dose comercial ocasionou controle superior a $80 \%$ para todas as espécies estudadas. Os herbicidas saflufenacil e mesotrione não foram eficazes no controle de $L$. aegyptiaca e $R$. communis, respectivamente. Dessa forma, foram observados diferentes níveis de suscetibilidade das espécies de plantas daninhas aos herbicidas aplicados em pós-emergência, sendo os mais eficazes amicarbazone e sulfentrazone.
\end{abstract}

Palavras-chave: Controle químico. Palha. Colheita mecanizada. Cana-de-açúcar.

\section{CONTROL OF WEEDS IN POST-EMERGENCE HERBICIDES USED IN CULTURE OF SUGAR CANE}

\begin{abstract}
The implantation of the mechanized harvesting system of sugarcane led to changes in the production system, in the production system was the modification of the weed flora, promoting the emergence of weed species that weren't present in the conventional production system where the sugar cane was burnt. The present work had the objective of determining dose response curves of the herbicides amicarbazone, saflufenacil, mesotrione and sulfentrazone in post-emergence, over the weed species Merremia aegyptia; Ipomoea purpurea; Luffa aegyptiaca; Mucuna aterrima e Ricinus communis. The experiment was conducted in a greenhouse, with delineation entirely randomized, with four repetitions. The treatments constituted of the spraying of different doses of the herbicides amicarbazone, saflufenacil, mesotrione and sulfentrazone over the weed plants M. aegyptia; I. purpurea; L. aegyptiaca; M. aterrima e R. communis when the plants had two pairs of true leaves. . The method used was the dose response curves, being sprayed doses equivalent to 1,$5 ; 1,0 ; 0,5 ; 0,25$ and 0,0 times the commercial dose of each product (amicarbazone, saflufenacil, mesotrione, and sulfentrazone). The herbicides were sprayed individually over each weed species,. By 7, 14 and 21 days after the applications of the treatments (DAT), the symptoms of phytotoxicity were visually evaluated, and by 21 DAT, the dry mass of the shoots was determined. The herbicides saflufenacil and mesotrione weren't effective in controlling Luffa aegyptiaca e Ricinus communis, respectively. The application of the herbicides sulfentrazone and amicarbazone resulted in control superior to $80 \%$ for all weed species times the commercial dose studied. Therefore, different levels of susceptibility of the weed plants to post-emergent herbicides were observed. The herbicides amicarbazone and sulfentrazone were the most effective.
\end{abstract}

Keywords: Chemical control, Straw, Mechanized harvest, Sugarcane.

\footnotetext{
*Autor para correspondência

${ }^{1}$ Recebido para publicação em 16/04/2014; aceito em 13/08/2015.

Parte da Dissertação de Mestrado do Curso de Pós-Graduação em Agricultura e Ambiente da CCA/UFSCar do primeiro autor.

${ }^{2}$ Aluno do Programa de Pós-Graduação em Agricultura e Ciências Agrárias - CCA-UFSCar, Rodovia Anhanguera.

${ }^{3}$ Professora associada do Departamento de Recursos Naturais do Centro de Ciências Agrárias - CCA-UFSCar, Rodovia Anhanguera, 13600-000 Araras (SP).

${ }^{4}$ Aluno de graduação do Centro de Ciências Agrárias - CCA-UFSCar, Rodovia Anhanguera, 13600-000 Araras (SP).
} 


\section{INTRODUÇ̃̃̃O}

A alteração do sistema convencional de produção da cana-de-açúcar, que utilizava fogo para operação de despalha, para o denominado "cana crua", termo utilizado para designar a colheita sem queima prévia do canavial, representou uma série de mudanças no sistema produtivo da cultura em virtude da quantidade de palha deixada sobre o solo após a colheita, que pode variar de 10 a $20 \mathrm{tha}^{-1}$ (SOUZA et al., 2005).

Dentre essas mudanças pode-se citar a alteração da flora infestante dos canaviais, pois algumas espécies antes predominantes, como Urochloa decumbens, Urochloa plantaginea, Panicum maximum e Digitaria horizontalisI, tiveram o desenvolvimento contido pela presença de palha sobre o solo (VELINE et al., 2000). Em contraposição, a palha estimulou a germinação de outras espécies que encontraram um ambiente mais favorável ao seu desenvolvimento, como Ipomoea triloba, Merremia aegyptia, Luffa aegyptiaca, Mucuna aterrima e Ricinus communis (MARTINS et al., 1999; ROSSI et al., 2006; MONQUERO et al., 2011a).

Os canaviais colhidos no sistema cana crua passaram a ter em sua flora infestante espécies de plantas daninhas que em sua maioria têm o ciclo de vida anual que termina após a maturação da cultura, com porte herbáceo, hábito de crescimento trepador, caule cilíndrico, sementes grandes (tendo um teor considerável de estrutura de reserva), dureza no tegumento e longo período e dormência. Em virtude dessas características essa nova flora infestante presente nos canaviais representam um entrave na colheita da cana-de-açúcar, prejudicando o desempenho operacional das colhedoras (LORENZI, 1994). Além disso, os canaviais cultivados sobre o sistema de cana-crua também apresentam espécies de hábito arbustivo, como, por exemplo, Ricinus communis.

Nessa nova composição da flora infestante surgiu a dificuldade de se encontrar herbicidas que ao mesmo tempo sejam seletivos a cultura e tenham eficiência no controle sobre as plantas daninhas em pós-emergência (CHRISTOFFOLETI et al., 2007). Alguns herbicidas têm sido frequentemente utilizados nos canaviais para o controle dessas espécies, dentre eles o saflufenacil, o qual inibe a protoporfirinogênio oxidase (PPO), ocasionando rápida desintegração da membrana, levando a um extravasamento do suco celular, necrose dos tecidos e morte das plantas (MENALLED, 2012). O sulfentrazone é outro herbicida registrado para a cultura da cana-deaçúcar que também atua inibindo a protoporfirinogênio oxidase (PROTOX), resultando no acúmulo da protoporfirinogênio no cloroplasto, dando origem ao oxigênio 'singlet' $\left(\mathrm{O}^{-}\right)$, provocando a peroxidação dos lipídeos das membranas e levando a célula a morte (CARVALHO; LÓPEZ-OVEJERO, 2008).

O mesotrione também é um herbicida frequentemente utilizado nos canaviais. Ele atua inibin- do a biossíntese de carotenoides através da interferência na atividade da enzima HPPD (4hidroxifenilpiruvato-dioxigenase) nos cloroplastos, sendo que a aplicação desse herbicida ocasiona o branqueamento das plantas sensíveis com posterior necrose e morte dos tecidos vegetais (LEE, 1997; WICHERT et al., 1999). Já o herbicida amicarbazone inibe a fotossíntese das plantas daninhas, atuando na reação de Hill (fotossistema II), interrompendo o transporte de elétrons e paralisando a fixação de $\mathrm{CO}_{2}$ e a produção de ATP e $\mathrm{NADPH}_{2}$, tendo como sintoma final a destruição das membranas e perda de clorofila (TOLEDO et al., 2009; CAVENAGHI et al., 2007).

O presente trabalho teve como objetivo determinar curvas de dose resposta dos herbicidas amicarbazone, saflufenacil, mesotrione e sulfentrazone em pós-emergência no controle das espécies de plantas daninhas Merremia aegyptia (L.) Urban, Ipomoea purpurea (L.) Roth, Luffa aegyptiaca Miller, Mucuna aterrima Piper e Tracy e Ricinus communis (L.).

\section{MATERIAL E MÉTODOS}

O ensaio foi conduzido em casa de vegetação pertencente ao Departamento de Recursos Naturais e Proteção Ambiental (DRNPA) do Centro de Ciências Agrárias/UFSCar, Araras (SP).

O delineamento experimental utilizado foi inteiramente casualizado, com quatro repetições. As unidades experimentais foram constituídas de vasos plásticos com capacidade de 1 litro (1L), preenchidos com solo oriundo da camada arável de um latossolo vermelho de textura argilosa previamente peneirado, cuja análise físico-química pode ser visualizada na Tabela 1.

As espécies Merremia aegyptia, Ipomoea purpúrea, Luffa aegyptiaca, Mucuna aterrima e Ricinus communis foram semeadas individualmente nos vasos. Após a emergência das plantas daninhas foi realizado o desbaste adotando-se a densidade de 5 plantas por vaso, objetivando uniformizar a área foliar e o estágio de desenvolvimento das plântulas a fim de minimizar a variabilidade experimental.

Os vasos foram mantidos em casa de vegetação e irrigados com $10 \mathrm{~mm}$ de água por dia, através da programação dos turnos de rega da estufa com fim a manter as plantas vivas e sem estresse hídrico. Quando as plantas se encontravam entre o segundo e o quarto pares de folhas verdadeiras os herbicidas amicarbazone $\left(D=1400 \mathrm{~g} \mathrm{ha}^{-1}\right)$, saflufenacil $(\mathrm{D}=50$ $\left.\mathrm{g} \mathrm{ha}^{-1}\right)$, mesotrione $\left(\mathrm{D}=120 \mathrm{~g} \mathrm{ha}^{-1}\right)$ e sulfentrazone $\left(\mathrm{D}=600 \mathrm{~g} \mathrm{ha}^{-1}\right)$ foram aplicados nas doses $1,5 \mathrm{D}$, $1,00 \mathrm{D}, 0,5 \mathrm{D}, 0,25 \mathrm{D}$ e $0,00 \mathrm{D}$, sendo $\mathrm{D}$ equivalente a dose recomendada. Salienta-se que para os tratamentos saflufenacil e mesotrione fora adicionado óleo mineral a calda, conforme recomendado pelo fabricante. 
Tabela 1.Características químicas e físicas da amostra de solo utilizada no experimento.

\begin{tabular}{cccccccccccccc}
\hline \multicolumn{10}{c}{ Latossolo Vermelho } \\
\hline $\mathbf{P}$ & M.O. & $\mathbf{p H}$ & $\mathbf{K}$ & $\mathbf{C a}$ & $\mathbf{M g}$ & $\mathbf{H}+\mathbf{A l}$ & $\mathbf{S B}$ & $\mathbf{C T C}$ & $\mathbf{V}$ & Argila & Areia & Silte \\
\hline $\mathrm{mg} / \mathrm{dm}^{3}$ & $\mathrm{~g} / \mathrm{dm}^{3}$ & $\mathrm{Ca} \mathrm{CI}$ & $\mathrm{mmol}_{\mathrm{c}} / \mathrm{dm}^{3}$ & & & & & & & \\
\hline 26 & 25 & 5,1 & 4,2 & 32 & 15 & 21 & 51,4 & 72,4 & 71 & 560 & $\mathrm{~g} \mathrm{~kg}^{-1}$ \\
\hline
\end{tabular}

Fonte: Laboratório de Química e Fertilidade dos Solos da UFSCar.

A aplicação foi realizada com um pulverizador costal pressurizado com $\mathrm{CO}_{2}$, provido de barra de pulverização contendo dois bicos tipo leque Teejet 110.02 , e com volume de aplicação de $200 \mathrm{~L} \mathrm{ha}^{-1}$. As condições ambientais no momento da aplicação foram umidade relativa do ar de $70,2 \%$, temperatura de $25{ }^{\circ} \mathrm{C}$ e velocidade do vento de $0 \mathrm{~km} \mathrm{~h}^{-1}$. Transcorrido o período de 24 horas após a aplicação dos herbicidas os vasos foram colocados em local definitivo em casa de vegetação.

Aos 7, 14 e 21 dias após as aplicações dos tratamentos (DAT) foram realizadas avaliações visuais baseadas nos critérios da ALAM (1974), a qual utiliza uma escala percentual de notas, em que 0 (Zero) corresponde a ausência de controle e 100\% o controle absoluto. Aos 21 DAT a parte aérea das plantas daninhas foram cortadas rente ao solo e na sequência acondicionadas em sacos de papel e levadas para uma estufa com circulação de ar forçada com temperatura constante de $60^{\circ} \mathrm{C}$ por dois dias para obtenção da massa seca.

Os dados da massa seca foram corrigidos para valores percentuais, partindo-se do princípio de que as parcelas que permaneceram sem aplicação de herbicida apresentaram $100 \%$ de massa seca e os demais percentuais valores, em consequência da redução imposta pelo herbicida.

Os dados obtidos foram submetidos a análise de variância pelo teste F. As médias foram comparadas por meio do teste de Tukey a $5 \%$ de probabilidade, utilizando-se o programa estatístico computacional ASSISTAT, cuja análise foi efetuada seguindo o esquema fatorial $5 \times 5$, sendo que no primeiro fator fora alocado as doses de herbicida e no segundo as plantas daninhas. Esse fatorial foi adotado de forma isolada para cada herbicida. Posteriormente, após a análise de variância, quando a interação dos fatores (Dose do herbicida e espécies de plantas daninhas) se mostrou significativa, os dados foram analisados com o emprego de regressões não lineares utilizando o programa estatístico Sigmaplot versão 10.0. No entanto, quando a interação dos fatores (Dose do herbicida e plantas daninhas) não se mostrou significativa, os medias foram apresentadas em tabelas.

\section{RESULTADOS E DISCUSSÃO}

Em relação ao herbicida amicarbazone, aos 7 DAT, constatou-se pela análise de variância interação significativa entre as doses e espécies (Figura 1 A). Aos 7 DAT na dose comercial nenhuma planta daninha foi controlada de forma satisfatória, ou seja, as porcentagens de controle foram inferiores a $80 \%$. $\mathrm{Na}$ dose de 1,50 D M. aterrima foi a única planta daninha que apresentou controle superior a $80 \%$. O herbicida resultou em controle inferior a $30 \%$ das plantas daninhas L.aegyptiaca, R.communis e I.purpurea.

A Mucuna aterrima é uma espécie caracterizada pelo acelerado desenvolvimento inicial, com grande produção de massa verde e intenso crescimento vegetativo em curto espaço de tempo (SOUZA; YAMASHITA 2006). Segundo Toledo et al. (2004), o herbicida amicarbazone atua no fotossistema II, inibindo o fotossíntese das plantas daninhas, e quando aplicado em pós-emergência inicial tem absorção foliar. Por ter rápido desenvolvimento vegetativo, as plantas de Mucuna aterrima no momento da aplicação do herbicida apresentaram maior área foliar do que as outras espécies de plantas daninhas avaliadas, e por esse motivo a absorção do herbicida amicarbazone pode ter sido maior, o que justifica os maiores níveis de fitoxicidade aos 7 DAT. Aos 14 DAT a interação entre as doses do herbicida e as espécies de plantas daninhas se mostrou significativa, sendo observado notória evolução dos níveis de controle, sendo que estes evoluíram e foram superiores a $90 \%$ em todas as doses estudadas aos 14 DAT (Figura 1B).

O período de avaliação de 21 DAT não apresentou interação significativa entre as doses do herbicida amicarbazone e as plantas daninhas, ou seja, não houve diferença entre as diferentes doses do herbicida e o níveis de controle observados nas espécies de plantas daninhas (Tabela 2). No entanto, através da análise das medias, observa-se que aos 21 DAT o amicarbazone resultou em pleno controle das espécies de plantas daninhas L.aegyptiaca, M.aterrima, R.communis, I.purpurea e M.aegyptia, independente da dose utilizada, ou seja, obteve-se porcentagens de controle superiores a $80 \%$ em todos os tratamentos. A dose comercial do herbicida (1400 $\mathrm{g} \mathrm{ha}^{-1}$ ) proporcionou controle superior a $90 \%$ para todas as espécies estudas, sendo esses níveis conside- 
(A)

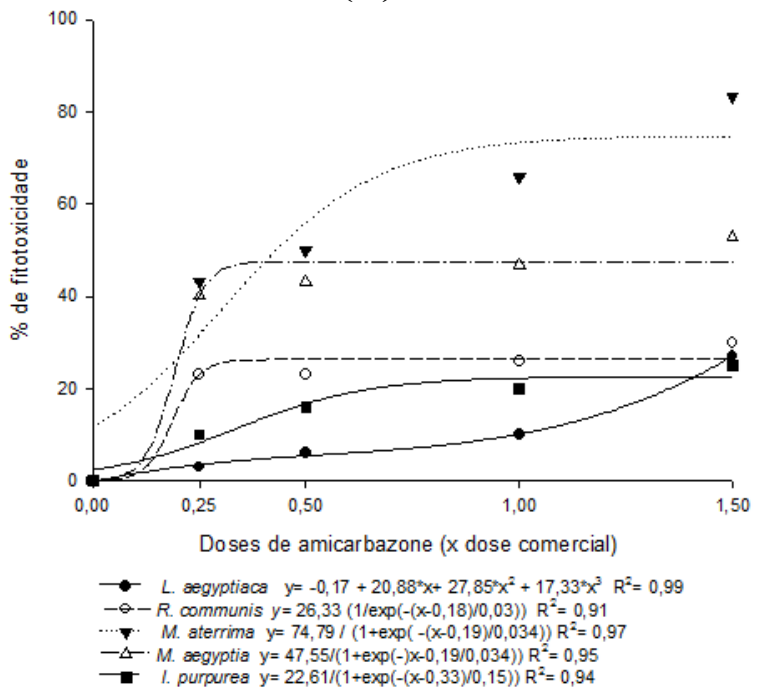

(B)

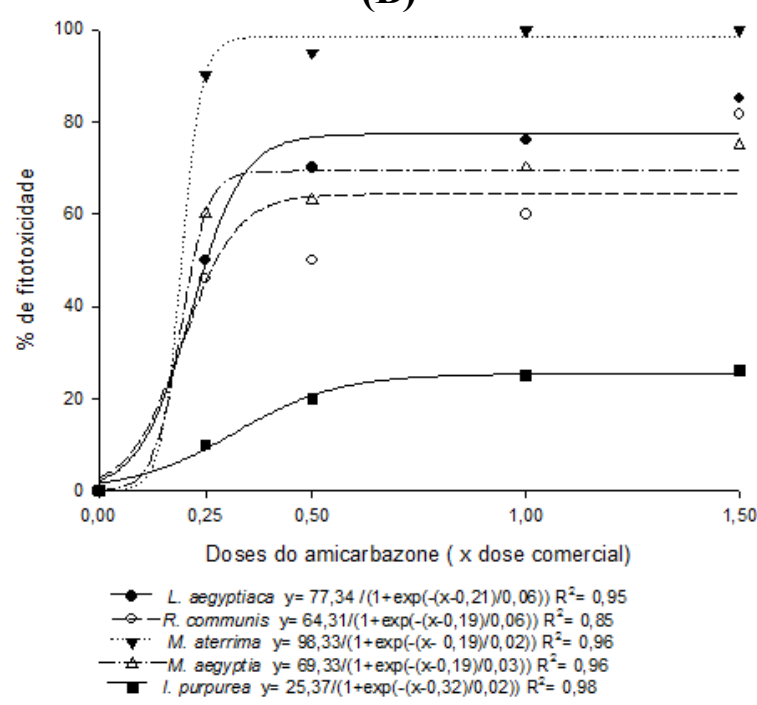

Figura 1. Porcentagem de controle (\%) das plantas daninhas Luffa aegyptiaca, Mucuna aterrima, Ricinus communis, Ipomoea purpurea e Merremia aegyptia pelo herbicida amicarbazone aos 7 DAT (A) e 14 DAT (B).

Tabela 2. Médias de controle (\%) das plantas daninhas L.aegyptiaca, M.aterrima, R.communis, I.purpurea e M.aegyptia aos 21 DAT do herbicida amicarbazone.

\begin{tabular}{|c|c|c|c|c|c|}
\hline \multirow[t]{2}{*}{ Espécies } & \multicolumn{5}{|c|}{ Dose (\%) } \\
\hline & O D & $0,25 \mathrm{D}$ & $0,50 \mathrm{D}$ & $1,0 \mathrm{D}$ & $1,5 \mathrm{D}$ \\
\hline L.aegyptiaca & 0,00 & 90,00 & 96,66 & 100,00 & 100,00 \\
\hline M.aterrima & 0,00 & 80,00 & 93,33 & 95,00 & 98,33 \\
\hline R.communis & 0,00 & 100,00 & 100,00 & 100,00 & 100,00 \\
\hline I.puprpurea & 0,00 & 100,00 & 100,00 & 100,00 & 100,00 \\
\hline M.aegyptia & 0,00 & 100,00 & 100,00 & 100,00 & 100,00 \\
\hline $\mathbf{F}_{\text {(espécie) }}=5,81 * *$ & \multicolumn{3}{|c|}{$\mathbf{F}_{(\mathrm{dose})}=130,03 * *$} & \multicolumn{2}{|c|}{$\mathbf{F}_{(\text {espécie } \mathbf{x} \text { dose })}=\mathrm{ns}$} \\
\hline \multicolumn{6}{|c|}{ C.V(\%) 6,00} \\
\hline
\end{tabular}

** = Significativo ao nível de $1 \%$ de probabilidade pelo teste $\mathrm{F}$ ); CV (coeficiente de variação).

No presente trabalho a aplicação do herbicida amicarbazone sobre as plantas da família convolvulácea (Merremia aegyptia e Ipomoea purpurea) não apresentou controle satisfatório aos 7 e 14 DAT. No entanto, aos 21 DAT o controle foi considerado excelente. Esses resultados podem ser justificados pelo metabolismo dessas plantas daninhas, onde o herbicida necessitou de um período de 21 dias após a aplicação dos tratamentos exercer plenamente a sua ação fitotóxica e resultar em controle satisfatório.

Perim et al. (2009) também obteve resultados semelhantes ao realizar experimento em casa de vegetação com o objetivo de verificar a eficácia de três doses do herbicida amicarbazone $(700 ; 1050 ; 1400 \mathrm{~g}$ i.a. ha $^{-1}$ ) no controle de Ipomoea grandifolia e Merremia cissoides, aplicado em pós-emergência. Nesse trabalho, os autores verificaram sintomas característicos do amicarbazone a partir dos 7 DAT. A dose de $1400 \mathrm{~g}$ i.a. ha ${ }^{-1}$ proporcionou excelente controle tanto para controlar Ipomoea grandifolia quanto para Merremia cissoides aos 14 DAT. As doses de 1050 e 700 g i.a. ha $^{-1}$ foram suficientes para controlar Ipomoea grandifolia e Merremia cissoides, respectivamente. Aos 21 DAT todas as doses do herbicida amicarbazone $\left(700 ; 1050 ; 1400 \mathrm{~g}\right.$ i.a. ha $\left.{ }^{-1}\right)$ apresentaram excelentes níveis de controle (100\%) para essas plantas daninhas.

Resultados semelhantes foram observados por Ramia et al. (2009), que através da aplicação da dose comercial do herbicida amicarbazone (1400 $\mathrm{g} \mathrm{ha}^{-1}$ ) na condição de pós-emergência inicial sobre Ricinus communis verificaram excelente controle (100\%) dessa planta daninha aos 21 DAT.

Aos 7 dias após a aplicação do herbicida amicarbazone as plantas de Luffa aegyptiaca apresentaram sintomas moderados, haja vista que em todas as doses utilizadas no estudo os níveis de controle permaneceram inferiores a $30 \%$. Aos 14 DAT os sintomas evoluíram, mas os níveis de controle permaneceram inferiores a $80 \%$ e apenas na dose 1,5 D obteve-se um controle superior a $80 \%$. Aos 21 DAT todas as doses do herbicida amicarbazone resultaram 
em um controle eficaz de Luffa aegyptiaca superior a 90\%. Esses resultados demonstram que inicialmente esse herbicida não apresentou um controle efetivo sobre Luffa aegyptiaca. No entanto, com a evolução dos DAT, os níveis de controle evoluíram e a eficácia de controle se tornou satisfatória.

Esses resultados corroboram com Pavani et al. (2012), que observaram aos 7 dias após a aplicação do herbicida amicarbazone em pós-emergência inicial de Luffa aegyptiaca, injúrias leves a moderadas, e aos 14 e 21 DAT injúrias severas. Os autores ainda relataram que a aplicação de amicarbazone realizada em plantas com menor porte (4 folhas) resultou na morte de Luffa aegyptiaca, mostrando que quanto mais inicial o estágio fenológico dessa planta maior a eficácia de controle do herbicida amicarbazone.

Em relação a massa seca da parte aérea das plantas daninhas para o amicarbazone, a interação entre as doses do herbicida e as plantas daninhas foi significativa. $\mathrm{O}$ aumento da dose do herbicida reduziu a massa seca de todas as plantas daninhas estudas (Luffa aegyptiaca, Mucuna aterrima, Ricinus communis, Ipomoea purpurea e Merremia aegyptia). Reduções mais expressivas foram observadas nas menores doses do herbicida, sendo que a dose comercial 1,00 $\mathrm{D}$ e $1,5 \mathrm{D}$ em valores próximos a zero em todas as espécies estudadas (Figura 2).

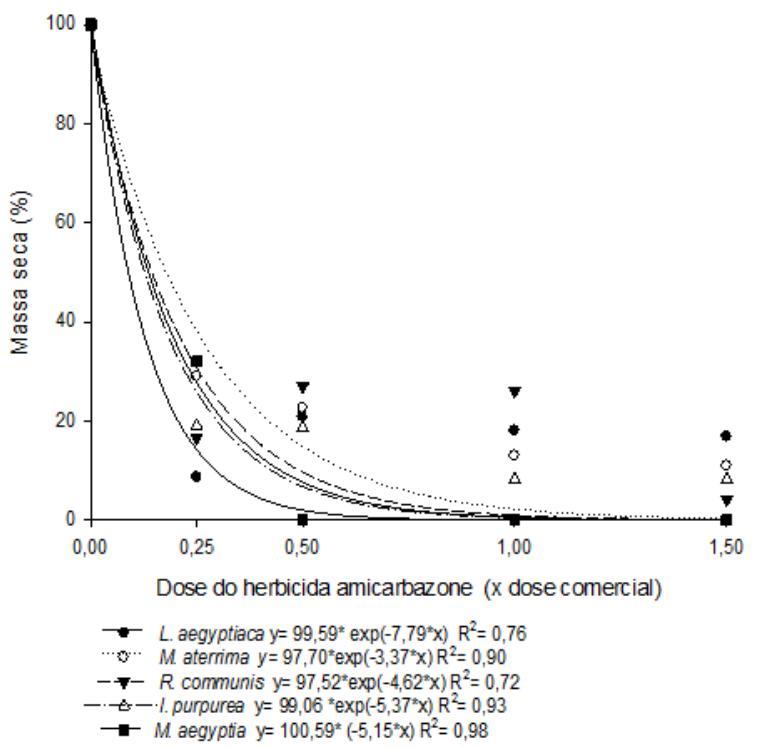

Figura 2. Massa seca (\%) das plantas daninhas Luffa aegyptiaca, Mucuna aterrima, Ricinus communis, Ipomoea purpurea e Merremia aegyptia, 21 DAT, do herbicida amicarbazone.

Para o herbicida saflufenacil aos 7 DAT, a interação entre as doses do herbicida e as espécies de plantas daninhas foi significativa (Figura 3A). Ipomoea purpurea e Ricinus communis apresentaram níveis de controle superiores a $80 \%$ para todas as doses estudadas. Já para Mucuna aterrima apenas a dose 0,25 D não foi eficaz no controle dessa planta daninha, apresentando uma porcentagem de controle inferior a $40 \%$. Merremia aegyptia não foi controlada de maneira eficiente em nenhuma dose do herbicida, apresentando porcentagens de controle inferiores a $60 \%$. E Luffa aegyptiaca foi controlada apenas na dose de 1,5 D (Figura 3A).

Aos 14 DAT houve diferença significativa. Ipomoea purpurea e Ricinus communis apresentaram níveis de controle superiores a $80 \%$ em todas as doses do herbicida saflufenacil. Já para a Mucuna aterrima a única dose que não foi eficaz no controle foi a de 0,25 D (nível inferior a 80\%). Em contrapartida, para Luffa aegyptiaca a única dose de saflufenacil que apresentou eficácia de controle foi a de 1,5 D. Nenhuma das doses o herbicida saflufenacil apresentou eficácia no controle de Merremia aegyptia
(Figura 3B).

Aos 21 DAT, a interação entre as doses do herbicida saflufenacil e as plantas daninhas foi significativa (Figura 3C). O herbicida saflufenacil não apresentou eficácia de controle sobre Luffa aegypti$c a$, pois a única dose que resultou em $100 \%$ de controle foi a de 1,5 D. Para Mucuna aterrima a dose de 0,25 D não foi efetiva no controle dessa espécie. As plantas de Ricinus communis e Ipomoea purpurea apresentaram alta suscetibilidade a esse herbicida, haja vista que em todas as doses os níveis de controle foram superiores a $80 \%$. Merremia aegyptia apresentou níveis de controle superiores a $80 \%$ apenas nas doses de 1,00 D e 1,50 D.

No presente estudo, verificou-se que o herbicida saflufenacil não mostrou eficácia no controle de Luffa aegyptiaca, pois apenas a dose equivalente $1,5 \mathrm{D}$ da recomendada pelo fabricante $(75 \mathrm{~g}$ ha $\left.{ }^{1}\right)$ apresentou resultados satisfatórios. No entanto, utilizar uma dose superior a recomendada em bula pode ocasionar danos relativos à seletividade da cultura da cana-de-açúcar, culminado em perda de produtividade. 
(A)

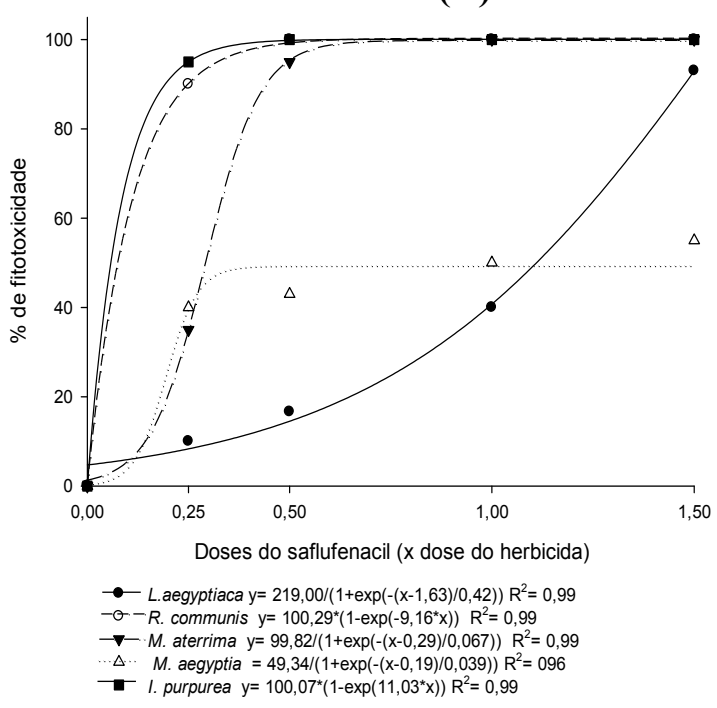

(B)

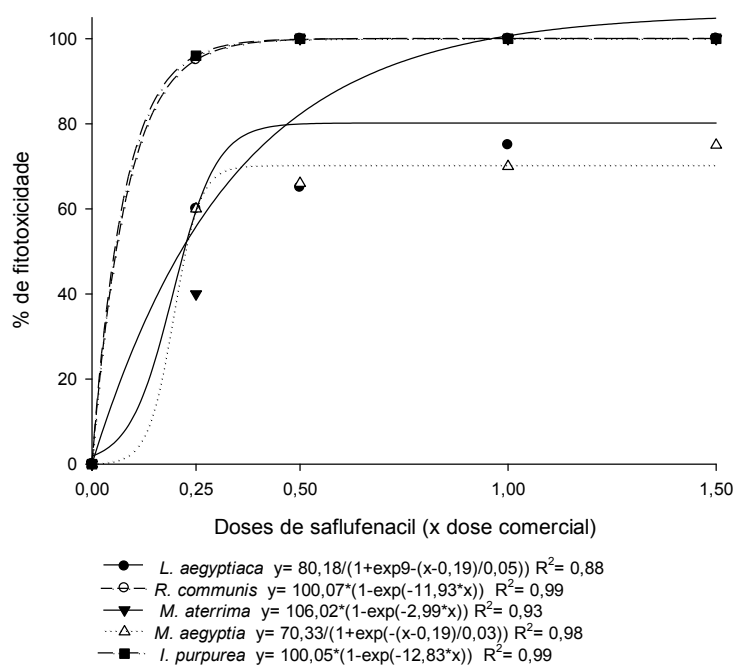

(C)

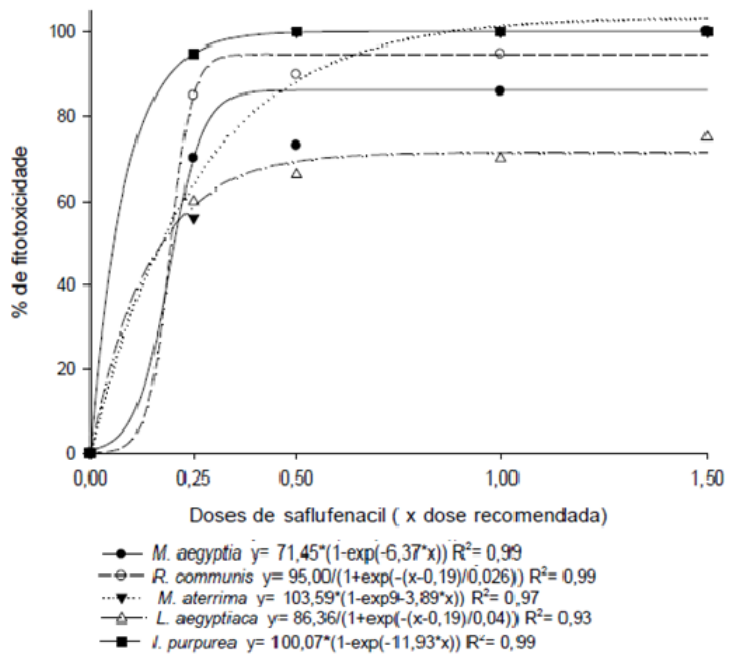

Figura 3. Porcentagem de controle (\%) das plantas daninhas Luffa aegyptiaca, Mucuna aterrima, Ricinus communis, Ipomoea purpurea e Merremia aegyptia pelo herbicida saflufnacil aos 7 DAT (A), 14 DAT (B) e 21 DAT (C).

Essa ineficácia do herbicida saflufenacil no controle de Luffa aegyptiaca pode estar associada a estrutura da superfície foliar dessa planta daninha. Alves et al. (2014), realizando microscopia eletrônica de varredura na superfície foliar da planta daninha Luffa aegyptiaca, aos 7 dias após a aplicação do herbicida saflufenacil, constataram a presença de tricomas tectores multicelulares e glandulares de ambos os lados (abaxial e adaxial), e uma ausência de cera epicuticular e estômatos anomocíticos. Também verificou que a aplicação do herbicida sobre Luffa aegyptiaca tornou as superfícies abaxial e adaxial mais ásperas e não afetou os tricomas. No mesmo trabalho, os autores relataram que a superfície da folha pode influenciar a deposição do herbicida, sendo que a presença de tricomas e glândulas podem deixar as células da epiderme completamente escondidas. Dessa forma, tricomas nas superfícies foliares podem interceptar gotículas, impedindo-as de atingir a epi- derme. No caso da Luffa aegyptiaca, a presença de tricomas tectores e glandulares podem ter interceptado o herbicida saflufenacil, evitando que esse produto entre em contato com as células da epiderme, ocasionando menor porcentagem de controle dessa planta daninha.

Os resultados obtidos no presente estudo corroboram com Monquero et al. (2011b), os quais visando o controle de Luffa aegyptiaca, Merremia cissoides, Mucuna aterrima e Ricinus communis, quando estas apresentavam o segundo par de folhas verdadeiras, realizaram um trabalho em casa de vegetação aplicando as doses $0 \mathrm{X}, 0,25 \mathrm{X}, 0,5 \mathrm{X}, 1 \mathrm{X}, 2 \mathrm{X}$, $4 \mathrm{X}, 8 \mathrm{X}$, sendo $\mathrm{X}$ a dose comercial recomendada do herbicida saflufenacil $\left(50 \mathrm{~g} \mathrm{ha}^{-1}\right)$. Nesse experimento os pesquisadores verificaram que aplicação do saflufenacil proporcionou um controle insatisfatório de Luffa aegyptiaca na dose recomendada $\left(50 \mathrm{~g} \mathrm{ha}^{-1}\right)$, e apenas com o dobro da dose comercial $\left(100 \mathrm{~g} \mathrm{ha}^{-1}\right)$ 
observou-se um controle de $80 \%$. Já Mucuna aterri$m a$ foi controlada de maneira eficiente pelo herbicida saflufenacil a partir da dose de $20 \mathrm{~g}$ i.a. ha ${ }^{-1}$, com controle superior a $80 \%$. Entretanto, o uso da dose comercial do produto $\left(50 \mathrm{~g} \mathrm{ha}^{-1}\right)$, por sua vez, proporcionou controle de $98,38 \%$. A espécie Ricinus communis foi satisfatoriamente controlada pelo saflufenacil em doses a partir de $20 \mathrm{~g} \mathrm{ha}^{-1}$. Em relação a Merremia cissoides, o controle também foi efetivo a partir de 16,90 $\mathrm{g} \mathrm{ha}^{-1}$.

Em relação ao herbicida saflufenacil, a interação entre as doses e as plantas daninhas foi significa- tiva para análise da massa seca aos 21 DAT (Figura 4). Notou-se uma redução da massa seca em todas as espécies estudadas na proporção em que se aumentou a dose do herbicida (Figura 4). Para Luffa aegyptiaca houve a menor redução dentre as espécies analisadas, sendo que na dose comercial essa redução foi inferior a $50 \%$. Esse comportamento também foi observado por Monquero et al. (2011b) para as espécies de Mucuna aterrima, Ricinus communis e Merremia cissoides, sendo que Luffa aegyptiaca apresentou uma redução de massa seca menos expressiva, demonstrando uma tolerância ao herbicida saflufenacil.

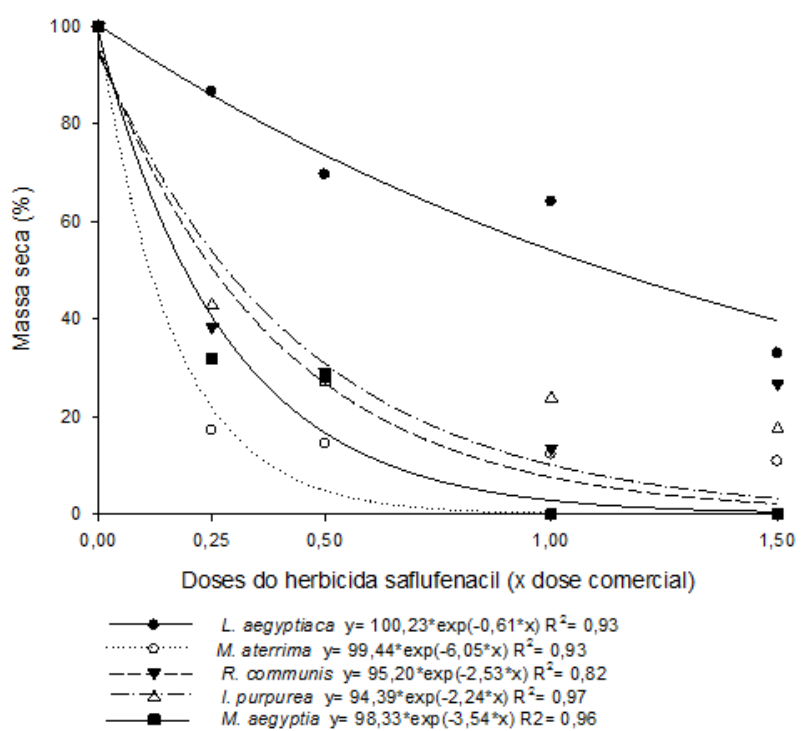

Figura 4. Massa seca (\%) das plantas daninhas Luffa aegyptiaca, Mucuna aterrima, Ricinus communis, Ipomoea purpurea e Merremia aegyptia aos 21 DAT do herbicida saflufenacil.

Em relação ao herbicida sulfentrazone, a interação entre as doses e as espécies de plantas daninhas foi significativa aos 7 DAT (Figura 5A). As plantas daninhas Ipomoea purpurea e Ricinus communis apresentaram níveis de controle superiores a $80 \%$ em todas as doses utilizadas no estudo $(0,25 \mathrm{D}, 0,50 \mathrm{D}$, 1,00 D e 1,50 D). Já Mucuna aterrima e Merremia aegyptia não foram controladas de maneira eficiente apenas na dose de $0,25 \mathrm{D}$, em que os níveis de controle foram inferiores $80 \%$. Luffa aegyptiaca apresentou a menor sucetibilidade ao controle pelo herbicida sulfentrazone, uma vez que a única dose que foi eficaz no controle dessa planta daninha foi a de 1,5 D.

Aos 14 DAT, para o herbicida sulfentrazone, a interação entre doses e plantas daninhas foi significativa. Aos 14 DAT a única planta daninha que não foi controlada de maneira eficaz foi Luffa aegyptiaca na dose de 0,25 D, obtendo-se uma porcentagem de controle inferior a $80 \%$ (Figura $5 \mathrm{~B}$ ).

Aos 21 DAT a aplicação do herbicida sulfentrazone foi significativa na interação entre doses e as plantas daninhas (Figura 5C). Ricinus communis, Ipomoea purpurea, Merremia aegyptia, Luffa aegyptiaca e Mucuna aterrima foram controladas de maneira eficaz em todos os tratamentos com porcentagens de controle superiores a $80 \%$.

Esses resultados demostram que o herbicida sulfentrazone pode ser considerado uma opção no controle de plantas daninhas nos canaviais, uma vez que apresentou alta eficácia de controle sobre plantas daninhas consideradas problemáticas na cultura da cana-de-açúcar colhidas sobre o sistema de cana crua.

Em relação a massa seca das plantas daninhas, a aplicação do herbicida sulfentrazone resultou em interação significativa entre as doses e as plantas daninhas (Figura 6), sendo que as Luffa aegyptiaca, Mucuna aterrima, Ricinus communis, Ipomoea purpurea e Merremia aegyptia apresentaram redução gradativa da massa seca medida que a dose do herbicida sulfentrazone se tornou maior (Figura 6). 
(A)

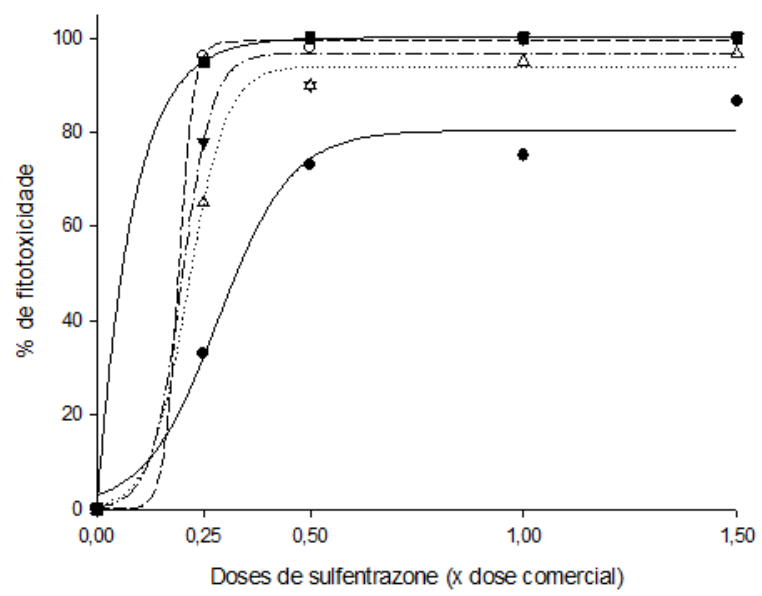

(B)

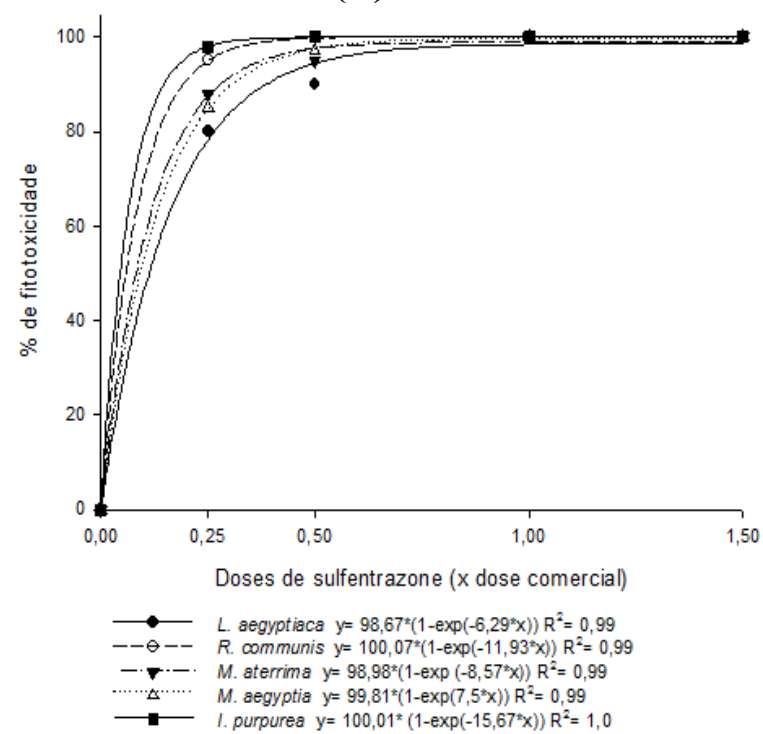

(C)

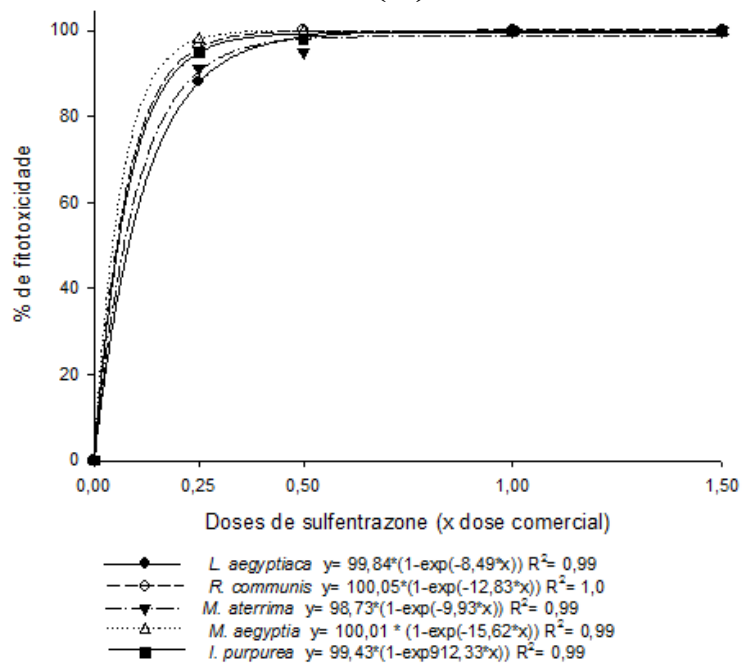

Figura 5. Porcentagem de controle (\%) das plantas daninhas Luffa aegyptiaca, Mucuna aterrima, Ricinus communis, Ipomoea purpurea e Merremia aegyptia pelo herbicida saflufenacil aos 7 DAT (A), 14 DAT (B) e 21 DAT (C).

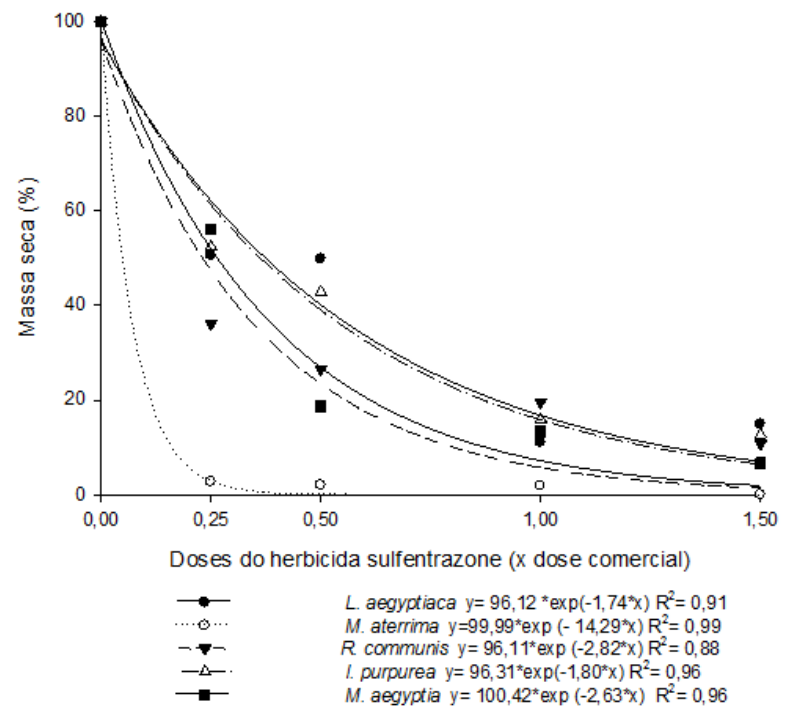

Figura 6. Massa seca (\%) das plantas daninhas Luffa aegyptiaca, Mucuna aterrima, Ricinus communis, Ipomoea purpurea e Merremia aegyptia aos 21 DAT do herbicida saflufenacil. 
Para o herbicida mesotrione aos 7 DAT não houve diferença estatística na interação entre as doses e as plantas daninhas (Tabela 3).

Em relação a avaliação de 14 DAT, a interação foi significativa entre as doses do herbicida mesotrione e as plantas daninhas (Figura 7A). Nessa avaliação a única espécie que foi controlada de maneira eficaz em todas as doses foi Mucuna aterrima. As maiores porcentagens de controle foram observadas em Ricinus communis. Já para Luffa aegyptiaca, Ipomoea purpurea e Merremia aegyptia o controle foi considerado ineficaz, com níveis inferiores a $80 \%$ (Figura 7A).Aos 21 DAT houve interação significati- va entre as doses de mesotrione e as espécies de plantas daninhas (Figura 7B). As espécies Mucuna aterrima e Ipomoea purpurea foram eficientemente controladas pelo herbicida mesotrione, sendo que em todas as doses estudadas foram observados níveis superiores a $80 \%$ de controle. Para Merremia aegyptia e Luffa aegyptiaca o controle foi ineficaz na dose de $0,25 \mathrm{D}$, com níveis inferiores a $80 \%$. Já a espécie Ricinus communis não foi controlada de maneira eficiente pelo herbicida mesotrione, com níveis inferiores a $70 \%$ em todas as doses estudadas (Figura 7B).

Tabela 3. Médias de controle (\%) das plantas daninhas L.aegyptiaca, M.aterrima, R.communis, I.purpurea e M.aegyptia aos 7 DAT do herbicida mesotrione.

\begin{tabular}{|c|c|c|c|c|c|}
\hline \multirow[t]{2}{*}{ Espécies } & \multicolumn{5}{|c|}{ Dose (\%) } \\
\hline & O D & $0,25 \mathrm{D}$ & $0,50 \mathrm{D}$ & $1,0 \mathrm{D}$ & $1,5 \mathrm{D}$ \\
\hline L.aegyptiaca & 0,00 & 0,00 & 6,66 & 13,33 & 26,66 \\
\hline M.aterrima & 0,00 & 13,33 & 16,66 & 23,33 & 30,00 \\
\hline R.communis & 0,00 & 56,66 & 70,00 & 75,00 & 80,00 \\
\hline I.puprpurea & 0,00 & 0,00 & 10,00 & 16,66 & 20,00 \\
\hline M.aegyptia & 0,00 & 23,33 & 30,00 & 33,33 & 36,66 \\
\hline $\mathbf{F}_{\text {(espécie) }}=218,50 * *$ & \multicolumn{3}{|c|}{$\mathbf{F}_{(\text {dose })=}=52,18 * *$} & \multicolumn{2}{|c|}{$\mathbf{F}_{\text {(espécie } \mathbf{x} \text { dose })}=\mathrm{ns}$} \\
\hline \multicolumn{6}{|c|}{ C.V(\%) 24,53} \\
\hline
\end{tabular}

**(significativo ao nível de $1 \%$ de probabilidade pelo teste $\mathrm{F}$ ); ns: não significativo; CV (coeficiente de variação).

(A)

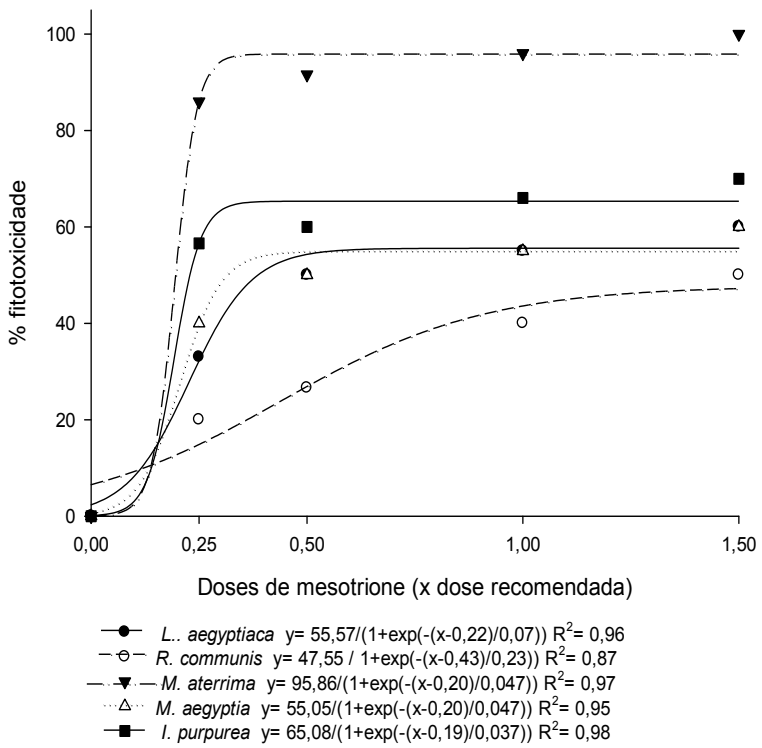

(B)

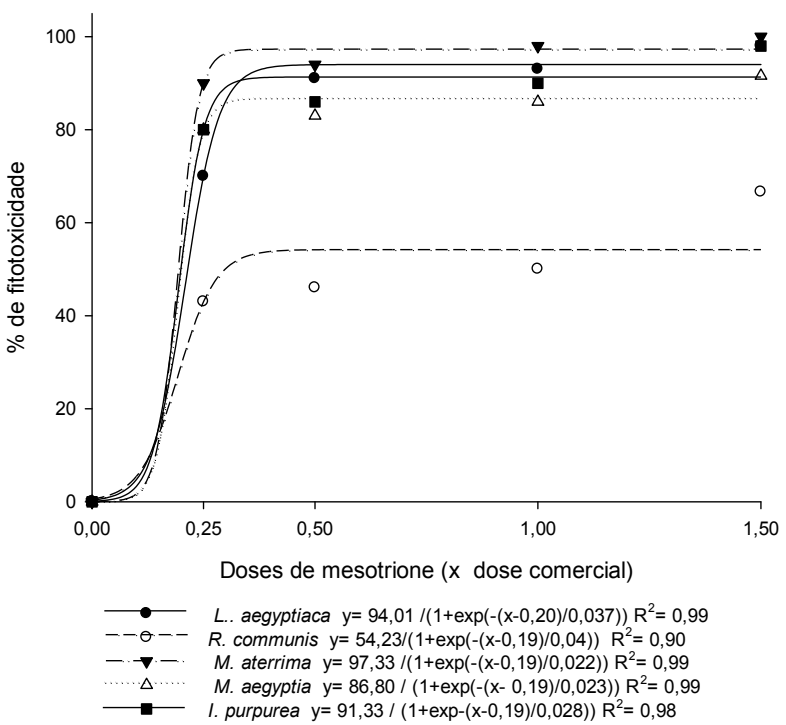

Figura 7. Porcentagem de controle (\%) das plantas daninhas Luffa aegyptiaca, Mucuna aterrima, Ricinus communis, Ipomoea purpurea e Merremia aegyptia pelo herbicida mesotrione aos 14 DAT (A) e 21 DAT (B).

Os resultados acima reforçam as observações realizadas nas avaliações visuais notando-se uma progressão dos sintomas de controle de forma mais lenta quando comparado com os demais herbicidas utilizados nesse estudo. Esse fato pode ser justificado pelo mecanismo de ação do herbicida mesotrione, que consiste na inibição da biossíntese de carotenóides por intermédio da interferência na atividade da enzima 4-hidroxifenilpiruvato-dioxigenase (4-HPPD) nos cloroplastos. Os sintomas envolvem 
branqueamento das plantas daninhas sensíveis com posterior necrose e morte dos tecidos vegetais em cerca de 1 a 2 semanas (LEE, 1997; WICHERT et al., 1999).

Monquero et al. (2009) também verificaram que a aplicação do herbicida mesotrione em pósemergência apresenta evolução dos sintomas de forma gradativa. Esses resultados foram verificados em trabalho realizado em lavoura comercial de canasoca onde se aplicou o herbicida mesotrione (120 e $192 \mathrm{~g}$ i.a. ha ${ }^{-1}$ ) na condição de pós-emergência das plantas daninhas Euphorbia heterophylla e Ipomoea grandifolia em jato dirigido sobre a palha, nas entrelinhas da cana-de-açúcar. Para Euphorbia heterophylla, os autores verificaram que aos 15 DAT o controle efetuado pelo mesotrione não foi considerado satisfatório em ambas as doses utilizadas, com controle inferior a $60 \%$. Para Ipomoea grandifolia, os autores verificaram ineficácia do mesotrione aos 15 DAT, com níveis de fitoxicidade inferiores a $80 \%$.

Em relação a Mucuna aterrima, Rogerio et al.
(2010) observaram que aos 14 DAT o controle dessa espécie não atingiu $100 \%$ mediante a aplicação de mesotrione (192 $\mathrm{g} \mathrm{ha}^{-1}$ ), e na última avaliação obteve-se morte das plantas de Mucuna aterrima, mostrando que esse tratamento foi efetivo no controle dessa planta daninha, mas apresentando evolução de sintomas de forma gradativa. Para a espécie Ipomoea hederifolia, a aplicação em pós-emergência do herbicida mesotrione ( $\left.240 \mathrm{~g} \mathrm{ha-}^{-1}\right)$ proporcionou um controle entre $80 \%$ e $90 \%$ aos 15 DAT, e aos 31 DAT um controle acima de 90\% (KUVA et al. 2010). Correia (2011) realizou a aplicação em pós-emergência do herbicida mesotrione (192 $\left.\mathrm{g} \mathrm{ha}^{-1}\right)$ sobre espécies da família convolvulácea obtendo controle de 85 a 95\% das espécies de Ipomoea hederifolia e Merremia aegyptia, aos 14 DAT.

Na aplicação de mesotrione houve interação significativa entre as doses do herbicida e plantas daninhas para massa seca em todas as espécies estudadas. Notou-se uma redução dos valores de massa seca em relação a testemunha na medida em que se aumentou a dose desse herbicida (Figura 8).

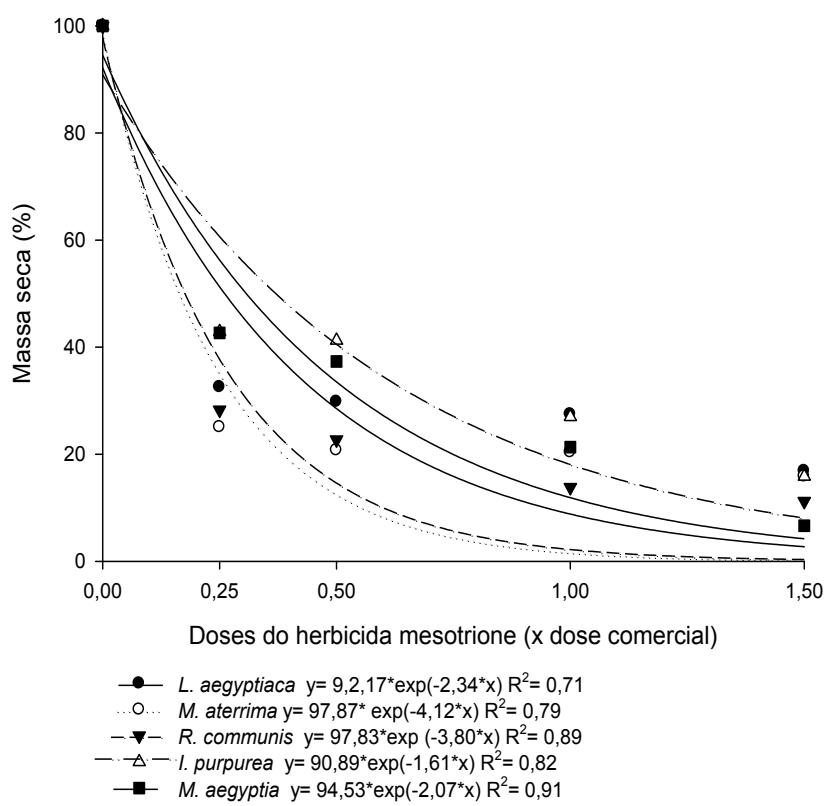

Figura 8. Massa seca (\%) das plantas daninhas Luffa aegyptiaca, Mucuna aterrima, Ricinus communis, Ipomoea purpurea e Merremia aegyptia aos 21 DAT do herbicida mesotrione.

\section{CONCLUSÃO}

As plantas daninhas Merremia aegyptia, Ipomoea purpúrea, Luffa aegyptiaca, Mucuna aterrima e Ricinus communis tiveram diferentes níveis de suscetibilidade aos herbicidas amicarbazone, saflufenacil, mesotrione e sulfentrazone quando aplicados em pós-emergência. O amicarbazone e sulfentrazone foram os herbicidas mais eficientes no controle das espécies estudadas.

\section{REFERÊNCIAS}

ASOCIATION LATINOAMERICANA DE MALEZAS. Recomendaciones sobre unificación de los sistemas de evaluación em ensayos de control de malezas. ALAM, Bogotá, v. 1, 1974.p. 35-38.

ALVES, R. M. et al. Leaf-surface characterization and the effects of the herbicide saflufenacil on the leaves of weeds. Agrária, Pernambuco, v. 9, n.4, p. $550-555,2014$.

CARVALHO, S. J. P.; LÓPEZ-OVEJERO, R. F. Resistência de plantas daninhas aos herbicidas inibidores da PROTOX (Grupo E). In: CHRISTOFFO- 
LETI, P. J. (Coord.). Aspectos de resistência de plantas daninhas a herbicidas. Piracicaba: HRACBR, 2008. p. 69-77.

CAVENAGHI, A. L. et al. Dinâmica do herbicida amicarbazone (Dinamic) aplicado sobre palha da cana-deaçúcar (Saccarum officinarum). Planta Daninha, Viçosa, v. 25, n. 4, p. 831-837, 2007.

CHRISTOFFOLETI, P. J. et al. Conservation of natural resources in Brazilian agriculture: implications on weed biology and management. Crop Protec, Durban, v. 26, n.3, p. 383-389, 2007.

CORREIA, N. M. Eficácia do mesotrione aplicado isolado e em mistura para o controle de corda-deviola e de mucuna preta em cana-soca. Álcoolbras, São Paulo, v.3, n. 133, 2011, p. 46-51.

KUVA, M. A. et al. Inserção do herbicida mesotrione no programa de manejo de corda-de-viola em áreas de vana-soca. In: XXVII Congresso Brasileiro da Ciência das Plantas Daninhas, 27., 2010, Ribeirão Preto. SBCPD/Funep, 2010. p.653-657

LEE, D. L. The discovery and strtural requirements of inihibitors of phydroyphenylpyruvate dioxygenase. Weed Science, Lawrence, v. 45, n.5, p. 601-609, 1997.

LORENZI, H. Plantas daninhas do Brasil. 4.ed. Nova Odessa: Plantarum, 1994. 440 p.

MARTINS, D. et al. Emergência em campo de dicotiledôneas infestantes em solo coberto com palha de cana-de-açúcar. Planta Daninha, Viçosa, v. 17, n.1, p. 151-161, 1999.

MENALLED, F. New herbicides have special uses. Montana State University. Disponível em: $<$ http://www.montana.edu/cpa/news/nwview.php? article $=5852>$. Acesso em: 03 de abril de 2012 .

MONQUERO, P. A. et al. Eficácia de herbicidas aplicados em diferentes épocas e espécies daninhas em áreas de cana-de-açúcar colhida mecanicamente. Planta Daninha, Viçosa, v. 27, n.2, p. 309-317, 2009.

MONQUERO, P. A. et al. Monitoramento do banco de sementes em áreas de cana-de-açúcar colhida mecanicamente. Planta Daninha, Viçosa, v. 29, n.1, p. 107-119, 2011a.

MONQUERO, P. A. et al., Saflufenacil no controle de Luffa aegyptiaca, Merremia cissoides, Mucuna aterrima e Ricinus communis. Revista Brasileira de Herbicidas, Londrina, v. 10, n.3, p. 176-182, 2011 b.

NICOLAI et al., Alternativas de manejo para as po- pulações de picão-preto (Bidens pilosa e Bidens subalternans) resistentes aos herbicidas inibidores da ALS. Revista Brasileira de Herbicidas, Londrina, v. 3, n.3, p. 72-79, 2006.

PAVANI, D. et al. Tolerância de Luffa aegyptiaca aos Herbicidas Aplicados em Diferentes Estádios de Crescimento. STAB, Piracicaba, v. 30, 2012, n.5, p. 46-49.

PERIM, L. et al. Eficácia do herbicida amicarbazone no controle em pós-emergência de corda-de-viola (Ipomoea grandifolia e Merremia cissoides). Revista Brasileira de Herbicidas, Londrina, v. 8, 2009, p. 19-26.

RAMIA, V. V. et al. Manejo Químico de Ricinus communis utilizando herbicidas seletivos À cana-deaçúcar. STAB, Piracicaba, v. 28, n.2, 2009, p. 38-41.

ROGERIO, A.C. et al. Eficácia do mesotrione aplicado isolado e em mistura no controle de mucuna preta na cultura da cana-de-açúcar. In: XXVII Congresso Brasileiro da Ciência das Plantas Daninhas, 27, 2010, Ribeirão Preto. SBCPD/Funep, 2010, p. $1279-1283$.

ROSSI, C. V. S. et al. Efeito da presença de palha de cana crua a germinação de plantas daninhas em época seca. In: CONGRESSO BRASILEIRO DA CIÊNCIA DAS PLANTAS DANINHAS, 25. 2006, Brasília. SBCPD/UNB; Embrapa Cerrados, 2006. p. 326-330.

SOUZA, M. F. P.; YAMASHITA, O. M. Potencial alelopático da mucuna-preta sobre a germinação de sementes de alface e picão preto. R. Ciência AgroAmbiental., Alta Floresta, v. 4, n. 1, p. 23-28, 2006.

SOUZA, Z. M. et al. Sistemas de colheita e manejo da palhada de cana-de-açúcar. Pesquisa Agropecuária Brasileira, Brasilia, v. 40, n. 3, 2005, p.271-278.

TOLEDO, R. E. B. et al. Eficácia do herbicida amicarbazone aplicado sobre a palha ou no solo no controle de plantas daninhas na cultura da cana-deaçúcar. Planta Daninha, Viçosa, v. 27, n. 2, p. 319 326, 2009.

TOLEDO, R. E. B. et al. Dinamic (Amicarbazone), novo herbicida seletivo para o controle de plantas daninhas em pré e pós emergência na cultura da cana -de-açúcar. In: CONGRESSO BRASILEIRO DA CIÊNCIA DAS PLANTAS DANINHAS, 24. 2004, São Pedro. SBCPD, 2004. p.245-249.

VELINI, E. D. et al. Efeito da palha da cana-deaçúcar sobre a germinação das principais espécies de plantas daninhas gramíneas desta cultura. In: CONGRESSO BRASILEIRO DA CIÊNCIA DAS 
PLANTAS DANINHAS, 22, 2000, Foz do Iguaçu. SBCPD, 2000. p. 15-19.

WITCHERT, R. A. et al. Technical over view of ZA1296, a new corn herbicide from ZENECA. Weed Science Society of America. Abstr. p. 39-65, 1999. 